\title{
The Influence of Socio-Cultural Beliefs in Chris Hani Baragwanath Academic Hospital (Chbah): A Social Work Perspective
}

\author{
Thobeka S. Nkomo \\ Department of Social Work, The University of the Witwatersrand, Johannesburg, Gauteng, South Africa \\ Email: Thobeka.nkomo@wits.ac.za
}

How to cite this paper: Nkomo, T.S. (2017) The Influence of Socio-Cultural Beliefs in Chris Hani Baragwanath Academic Hospital (Chbah): A Social Work Perspective. Open Journal of Social Sciences, 5, 4659.

https://doi.org/10.4236/jss.2017.58004

Received: May 12, 2017

Accepted: August 1, 2017

Published: August 4, 2017

Copyright $\odot 2017$ by author and Scientific Research Publishing Inc. This work is licensed under the Creative Commons Attribution International License (CC BY 4.0).

http://creativecommons.org/licenses/by/4.0/

\section{cc) (i) Open Access}

\begin{abstract}
Background: Socio-cultural beliefs play a significant role in healthcare as they influence perceptions of health and illness for both the client and the healthcare provider. These beliefs may influence the need to use a variety of health care providers. By understanding the belief system of patients, clinical social workers can effectively meet the needs of the hospital patients. The aim of this paper was to explore the role of patients' socio-cultural beliefs in a healthcare setting. Methodology: By means of an exploratory investigation with 24 patients at an academic hospital in Gauteng, this paper identifies some beliefs that patients bring with them into the healthcare institution. Herskovits in-depth relativist approach was used to analyze the data. This paper examines how beliefs contradict, enhance or complement clients' experiences of health care within a hospital setting. The results illustrate that African traditional and cultural beliefs were reported to be affordable and enable people to connect with their ancestral spirits. Close relatives and traditional healers played an important role during illness and recovery. It is recommended that social workers should always engage with patients and other members of multi-disciplinary team for a holistic patient care approach. Social workers should communicate to holistically understand their patients.
\end{abstract}

\section{Keywords}

Culture, Gauteng, Socio-Cultural Beliefs, Social Work, Healthcare

\section{Introduction}

According to Petrus and Bogapa (2007) [1], every society has its own traditional beliefs and practices related to health and wellbeing. South African communities 
have numerous religious and cultural beliefs systems. As a result, beliefs in supernatural powers are prevalent in many communities throughout South Africa. This is particularly so in rural areas where a significant number of people have not abandoned their traditions and practices (Petrus \& Bogopa, 2007) [1]. These beliefs are often reflected by the practice of a number of rituals that usually include offerings and sacrifices at various stages of human life from birth to death (Petrus \& Bogopa, 2007) [1].

Today, most social scientists view culture as consisting primarily of the symbolic, ideational, and intangible aspects of human societies (Ghiasuddin, Wong \& Siu, 2016) [2]. The essence of a culture is not its artifacts, tools, or other tangible cultural elements but how the members of the group interpret, use, and perceive them (Ghiasuddin, Wong \& Siu, 2016) [2]. "It is the values, symbols, interpretations, and perspectives that distinguish one people from another in modernized societies; it is not material objects and other tangible aspects of human societies" (Banks and McGee, 1989: 28) [3]. Therefore, it is common for people within a specific cultural practice to usually interpret the meaning of symbols, artifacts, and behaviors in the same or very similar ways (Ghiasuddin, Wong, \& Siu, 2016) $[2]$.

\section{Beliefs and Healthcare}

South African society embraces both faith and traditional healing practices in addition to Western medical pluralism (Yen \& Willbraham, 2003) [4]. Some of these healing modalities have been found to be effective while others have been proven to be harmful to people's health and well-being (Armernakis \& Kiefer, 2007; Yen \& Willbraham, 2003) [5].

Faith healing refers to a particular faith-based belief: for example, Hindu (Marquit, 2006) [6] and African traditional healing (Sobiecki, 2016) [7]. These are seen as alternatives to Western biomedicine, which predominates globally. According to Webster (2005) [8], a belief is a feeling of being sure someone or something exists or that something is true. For the purpose of this paper, socio-cultural beliefs will further include beliefs and rituals (Juckett, 2005) [9].

A socio-cultural approach will be used to unpack these beliefs. Bierwiaczonek and Waldzus (2016) [10] understand the socio-cultural approach as a theory based on the idea that society and culture shape one's cognition. Social customs, beliefs, and values are all part of what shapes a person's identity and reality (Bierwiaczonek \& Waldzus, 2016) [10]. According to this approach, a person's thoughts are based on his or her socio-cultural background. A socio-cultural approach takes into account more than the individual in attempting to understand healing processes (Armernakis \& Kiefer, 2007; Bierwiaczonek \& Waldzus, 2016) [5]. For the purpose of this study, socio-cultural beliefs will include culture, religion and faith (Armenakis \& Kiefer, 2007) [5].

Clinical social work is an old profession and in the last few years, has become a common area of practice in South Africa. Clinical social workers work closely 
with communities and are commonly based in hospitals and clinics (Dorfmann, Meyer \& Morgan, 2012; Cooper \& Lesser, 2008) [11]. Clinical social workers address a variety of health, psychological and social inter-related conditions such as stress and depression (Sheafor \& Horejsi, 2010) [12]. These professionals are often confronted with patients who present problems which can be best understood in relation to their social and cultural backgrounds (Cooper \& Lesser, 2008) [13].

Each society has its own socio-cultural beliefs needing to be appreciated by social and health professionals (Dorfmann et al., 2012) [11]. Hence, it is important clinical social workers possess some understanding of the local context as well asdominant cultural values and beliefs (Dorfmann et al., 2012) [11]. A better understanding of patient/or client cultural beliefs will help improve interaction between the client/or patient and health practitioner (Seupaul \& Jones, 2002; Dorfmann et al., 2012) [14].

The literature indicates not all traditional customs and beliefs are harmful to people (Ginger \& Davidhizar, 2004) [15]. For example, in the Xhosa culture there is a common cultural practice called ukuthomba. Ukuthomba. It is a cultural way of acknowledging a girl child has entered womanhood and have positive values (Ginger \& Davidhizar, 2004) [15]; other practices, such as ukusoka, translated as circumcision either for girls or boys, may be harmful (Kangwa \& Catron, 2011) [16].

A person's cultural background often influences how they gain entry into the healthcare system and adherence to medication and treatment. All these factors play an important role in the eventual recovery of the patient from illness (Kangwa \& Catron, 2011) [16]. It is important health professionals acknowledge and recognize their patients' social-cultural differences in relation to modern scientific medicine.

Various studies have provided evidence that socio-cultural differences between clients and healthcare practitioners can have an effect on the relationship between the patient and the healthcare professional (i.e. nurse, psychologist, medical doctor etc.). Additionally, the state of the relationship often impacts the quality of healthcare provided to the client (Cooper \& Lesser, 2008) [13]. This also applies to social work as a clinical social worker needs to provide the most effective and holistic care possible (Cooper \& Lesser, 2008) [13]. If patient holistic care is to be realized, one needs to understand the social-cultural background of the client as a factor. This often determines what the patient deems a priority (Ghiasuddin et al., 2016; Delgado \& Rohani, 2005) [2]. This is because some patients value the cultural explanation of diseases rather than those provided by health professionals in healthcare settings (Ghiasuddin et al., 2016) [2].

This exploratory investigation was undertaken as part of the development of indigenous clinical social work where clients' and patients' perceptions and experiences are viewed as valuable and necessary sources of knowledge for healthcare practitioners. 


\section{Purpose of the Study}

This article presents findings on how socio-cultural beliefs influence healthcare seeking and service provision.

\section{Context of the Study}

Chris Hani Baragwanath Academic Hospital is one of the largest hospitals in South Africa as well as in the world (Turner, 2013) [17]. The hospital is currently able to accommodate more than 3200 patients with over 6760 staff members (Turner, 2013) [17]. The majority of staff members are of African origin and trained professionals. Employees at the hospital include specialists, surgeons, professional nurses, clinical nurses, clinical social workers and psychologists (Turner, 2013; Horwitz, 2013) [17]. The hospital is located in Soweto, Johannesburg, South Africa.

In contributing to evidence-based practice and knowledge, the hospital serves as a teaching facility for the University of the Witwatersrand, Faculty of the Health Sciences (Turner, 2013) [17]. Medical, pharmacy and nursing students are placed at the facility to be trained and supervised by experts (Turner, 2013; Horwitz, 2013) [17].

\subsection{Contribution to Existing Knowledge}

South Africa is currently one of the countries with highest inequality amongst its people. The poor still find it difficult to access essential services such as basic healthcare and education (Patel, 2005) [18]. In attempting to address this issue, the South African Council Social Service on Social Services Professionals (SACSSP) developed a code of ethics which serves to govern the roles of social services practitioners including social workers in healthcare settings (SACSSP, 2012) [19]. SACSSP is a South African professional body which accredits social work education. The body also regulates the practices and conduct of social workers (SACSSP, 2012) [19].

One particular stipulation in the Code of Ethics as enshrined in the SACSSP practice guidelines is the importance of cultural competence training in social work education and training (SACSSP, 2012) [19]. These standards require all South African social work and social auxiliary graduates understand the various forms and mechanisms of oppression and discrimination when they interact with their clients.

Academics in institutions of higher learning should make certain students are equipped with knowledge ensuring they behave in a way which is inclusive of respect for clients' social and cultural differences (NASW, 2001) [20]. However, there have been questions and concerns about whether the current caliber of social work academics are fit enough to develop curriculum which is context relevant and also will teach students in a manner to improve their appreciation of cultural differences within their clientele (SACSSP, 2012) [19].

There is also extensive literature and research addressing cultural belief and 
healthcare. Scholars are beginning to acknowledge individuals hold differing cultural and belief systems and these play a significant role in their healing (Kangwa \& Catron, 2011; Ginger \& Davidhizar, 2004) [16]. Therefore, it is imperative social workers have some understanding of this significance.

\subsection{The Relevance of Socio-Cultural Beliefs in Healthcare}

Juckett (2005) [9] acknowledges cultural competency as a skill is very important in the helping professions, particularly in the healthcare setting and social welfare sectors were professionals are interacting with assorted people daily. Juckett (2005, p. 2) [9] adds "the initial consultation interview should elicit the patient's perception of the illness and any potential cultural conflicts between the physician and patient including differing attitudes towards time and what is important in life".

Efforts directed toward instituting more culturally relevant healthcare to enrich the physician-patient relationship and improve patient rapport, adherence, and outcomes should be made (Juckket, 2005; Cooper \& Lesser, 2008) [9]. Therefore, it is critical socio-cultural beliefs predominant in the hospital are presented to healthcare professionals as guidelines (Cooper \& Lesser, 2008) [11]. These guidelines should be easily accessed by healthcare practitioners and can also be used as part of an orientation program or in-service training for new recruits (Cooper \& Lesser, 2008) [11].

A responsive healthcare system should always be considerate of cultural beliefs as reflected in each context (Ginger \& Davidhizar, 2007) [15]. The Western orientation to healthcare often makes it difficult for healthcare practitioners to adequately understand and offer support to African people, particularly to those who still believe in supernatural powers (Kangwa \& Castron, 2011) [16]. It is not surprising, for example, that a dominant theme in Western medicine has been to fight or vanquish disease (Kangwa \& Catron, 2011) [16], while in the traditional medical systems of the East, the prevailing image in healthcare is one of balance (Shetty, 2010) [18]. Therefore, relativism seeks to return balance and soul to Western healthcare (Shetty, 2010) [18].

\subsection{Social Work Practice and Socio-Cultural Beliefs}

Social workers practicing in hospitals and other health facilities need to utilize strategies actively engaging social and health issues of the poor and marginalized (Cooper \& Lesser, 2008) [11]. However, current approaches are often dismissive to indigenous people and old practices are often considered harmful and onerous (Cooper \& Lesser, 2008) [11].

Nevertheless, a patient is a member of society, and each society has a variety of social, cultural, political and economic factors which influence the patient's way of thinking. As a result, indigenous people in most African societies tend to have various explanations concerning ill health. As alluded to earlier on such explanations have influence over whether or not the person will seek medical care 
(Arrendondo \& Toporek, 2004; Cooper \& Lesser, 2008) [21].

Carter (1995 [22]) introduces a multicultural approach. This technique can be used by social workers to work with clients who come from distinct cultural orientations. Multicultural practice in clinical settings is an approach which combines the patients' lived experience-their own culture-and the mainstream culture, which is often Western in orientation (Carter, 1995) [22]. This approach ensures client uniqueness is appreciated while not neglecting the mainstream culture (Carter, 1995) [22]. There has been overwhelming evidence of patients responding and adhering well to medical care when clinical social workers integrate client beliefs systems into the mainstream healthcare options (Carter, 1995; Cooper \& Lesser, 2008 [21]).

\section{The Study Site}

The study was undertaken at Chris Hani Academic Hospital (CHABH) located at Soweto in Johannesburg, South Africa (Turner, 2013) [17]. The hospital is one of the 40 Gauteng provincial hospitals and is financed and run by Gauteng Provincial Health Authorities (Turner, 2013) [17]. CHABH also serves as teaching hospital for the University of the Witwatersrand Health Science Faculty along with the Charlotte Maxeke Johannesburg Academic Hospital, Helen Joseph Hospital and Rahima Moosa Mother and Child Hospital (Horwitz, 2013; Turner, 2013) [23].

As a training hospital, it is well equipped and motivated to serve the sick and injured as well as to maintain and defend truth, integrity and justice for all, at all times, to the benefit of patients, staff and the community (Horwitz, 2013) [23]. By working with leading universities, the hospital is able to contribute to evidence based practice and influence policy (Turner, 2013) [19]. Furthermore, the hospital strives to achieve the highest level of patient care which is based on sound scientific principles, administered with empathy and insight (Horwitz, 2013) [23].

Soweto is a community in flux-belonging to both the first and third worlds. By recording and documenting the change in diseases and pathology, $\mathrm{CHABH}$ provides guidance to all who face similar situations worldwide (Horwitz, 2013) [23]. As a social worker employed by $\mathrm{CHBAH}$, the researcher interacted with patients who had visited the hospital for various medical reasons. On several occasions, she was called for consultation with patients who had visited the hospital for surgical, medical or psychosocial reasons.

The CHBAH healthcare staff complement is predominantly African, and based on this observation it is assumed the understanding of socio-cultural aspects of each and every patient when one is not from an African background is likely to be a challenge. Furthermore, the researcher's interactions and observation proved that social-cultural relevance should not be assumed when dealing with patients, irrespective of the attending staff being African or non-African, as cultural beliefs are diverse. 


\section{Methods}

The study employed qualitative approach which was exploratory, descriptive and contextual. According to Babbie and Mouton (2001) [24], a qualitative research approach allows the researcher to understand a phenomenon as shared by the participants. In-depth interviews were used to collect data. In-depth interviews are a means of understanding the lived experiences of other people and the meaning they take out of that experience (Babbie \& Mouton, 2001) [24].

Interviews are an interaction between the interviewer and the respondent in which the interviewer has a general plan but not a specific set of questions to be asked using particular words or a particular order (Babbie \& Mouton, 2001). The phenomenological approach was also used to reflect socio-cultural beliefs influencing healthcare provision at the CHBAH. According to Crabtree and Miller (1999: 28) [25] the phenomenological approach aims at uncovering the lived experience of study subjects.

\subsection{Data Collection}

This study was conducted in a hospital setting-CHBAH. All participants were patients at the institution. A semi-structured interview was used to collect data. The semi-structured interview contained open-ended questions, and they were asked primarily in English. However, when necessary, IsiXhosa, IsiZulu, Northern Sotho or Setswana were used to collect the data. The purpose of using some South African languages was to ensure participants entirely understood the interview questions. The length of the interviews ranged between 30 - 60 minutes per participant. All the participants were interviewed within the physical environment and socio-cultural belief system in which they were admitted at the time. The data was analyzed using the thematic content analysis method. This allowed the researcher to identify, induce themes and analyze the data.

\subsection{The Study Participants}

Twenty-five patients (25) took part in the study. All participants were selected through a purposive sampling technique. The age range was 21 to 65 years, 65 percent were women and 35 percent were men. Sixteen of the respondents were from an Nguni-speaking background meaning they either could speak and or understand IsiZulu or IsiXhosa. Six were from a Tswana-speaking background and three were from a Northern Sotho-speaking background. The researcher understood and could express herself in all four languages, which could be viewed as an advantage to minimize information distortions.

Thirty of the respondents honored their ancestors. For example, they performed traditional rituals as a form of isingxengxezo, meaning asking or informing their ancestors about the illness. Fifteen were affiliated to various religions. In discussing the results, the focus will be on six quotes which were considered critical and relevant to the study. It is generally assumed all Africans are the same or can believe in both ancestral worship and Christianity. However, in 
many instances this researcher encountered African patients who exclusively believed in traditional ways of dealing with their health related matters.

\subsection{Data Analysis}

Descriptive analysis was employed to analyze the data. According to Creswell (1994) [26] descriptive data analysis is comprised of a variety of steps were the researcher unpacks qualitative data for a richer analysis. In this study, the following steps were undertaken, as prescribed by Tesch (in Creswell, 1994) [26].

- The researcher familiarized herself with the data by reading through the transcriptions and field notes repeatedly.

- The first step enabled the researcher to obtain an idea of the data and as a result wrote down main points.

- Identification of recurring themes and clustering those which are similar.

- Encoding topics.

- Generating descriptive wording for topics and turning them into categories.

- Reducing topics by grouping those that were related (this serves as a basis for literature control).

- Alphabetizing these codes.

- Assembling data according to categories and conducting a preliminary analysis.

- Recoding existing data where necessary.

(Creswell, 1994) [26]

To ensure reliability of the data, an independent coder was used. The independent coder analyzed the data, and the themes. Sub-themes were finalized by the researcher and the supervisor through consensus discussion. Literature control was also used to verify these findings. The researcher further took steps to establish data trustworthiness. This included credibility and confirmability testing of the data

\section{Ethical Considerations}

The researcher adhered to the following ethical principles throughout the study. The researcher was aware this study may inflict emotional or psychological harm. For that reason, steps were taken to eradicate the possibility. All participants were protected from any physical and psychological harm, and were informed of the possible impact of the study.

The researcher also obtained informed consent from all participants. Strydom and Venter (2002) [27] stress the importance of ensuring participants do not feel coerced to participate in the study. It was agreed all information pertaining to the study should be disclosed to all participants. The researcher achieved this by explaining to all prospective participants what the study was about; the goal of the study; duration of each interview and the study methodology. Participants were further informed their participations are entirely voluntary. This information helped the participants to make informed decisions about whether or not to 
take part in the study.

In addition, steps were taken to ensure participants' anonymity and confidentiality. The researcher ensured research subjects' right to privacy by not revealing their names; interviews were conducted privately in a counseling room; cassette tapes were wiped clean following transcription of the research report. Additionally, participants were informed the study was authorized by the University Medical Ethics Committee.

\section{Findings and Discussion}

By way of demonstrating the relevance and significance of this paper, a few representative quotes drawn from the researcher's interaction and observation offerinsights into how socio-cultural beliefs might influence healthcare in a hospital are provided. The researcher witnessed and intervened in a situation where $\mathrm{Mr}$ " $X$ " requested to be released to visit his family and consult with his ancestors before a planned procedure. The medical practitioner could not understand him when he said "Ndiyavumaukuhlinzwa kodwa ndicela ukuya ekhaya ndithethe nezinyanya." This translates as "I do consent to the operation, but I need to visit my ancestors at home (Transkei)."

The practitioner interpreted this request as a delaying tactic. The researcher understood the significance the patient's request in terms of the belief that the success of the operation depended on his consultation with the ancestors. This request was then conveyed to the medical practitioner who then allowed the patient to visit his family.

In another incident, a patient diagnosed with a psychotic disorder was admitted repeatedly, and he also requested to consult with his traditional healer for treatment:

"Ukubano inyanga nokuphuza imithi yesintu yikho okwalaphayo. Isifo esifana nesi asalaphek i ngamayeza esilungu." This translates as, "Diseases like this cannot be treated with Western medication."

As a social worker, based on her understanding and cultural beliefs, the researcher was able acquiesce to the other healthcare professionals and patients. This was because I was able to explain to the patient that the medical staff was not against the consultation. However, the recurring admission could have been related to not taking or mixing the medication (traditional and Western). Based on this, an educational health talk had to be given to the patient and the patient's significant others.

For example, a woman of the African tradition had to be taken to the operating theatre. Just before the preparation her mother-in-law visited her in the ward. The patient had not covered her head. She was extremely upset that she had not been informed that the mother-in-law was visiting and she felt embarrassed. For her, this was a sign that something was not going to come right in theatre. As a form of voicing her frustration, she said "Into yokokuba ndifumaneke ndihamba ngentloko phambi komamazala lihlazo, kwaye ihlola okubi”. 
Translated, this means, "The fact that my mother-in-law found me with a bare head is the sign that this operation is not going to be a success as I have disrespected the ancestors."

Other healthcare professionals who were with the woman could not understand the source of her anger. I then intervened and spoke to her and to her mother separately and I did a joint session as I understood where she was coming from. The woman calmed down and was ready for the procedure.

Many cultural norms may influence patients' behavior and appearance (Cooper \& Lasser, 2008) [11]. Understanding, accepting, and respecting differences in lifestyle, beliefs, and customs is essential for building trusting interactions with your patients (Cooper \& Lasser, 2008; Carter, 1995) [11]. These are some of the norms that may be determined by your patients' culture and beliefs e.g. decision making.

Another patient said, "Thina ngesintu asinekelani ngegazi kuba izinyanya ziyakukumangalela." This means, "I cannot donate blood, because if I do donate or receive blood from someone else, my ancestors will rebel or turn against me." Blood transfusion is culturally and religiously unacceptable: one participant said, "Just imagine taking someone's blood in my family." Cultural beliefs influence health-related behavior all the time (Delgado, Jones \& Rohani, 2005) [28].

Consider the Jehovah's Witnesses' spiritual concern that translates into refusal of blood transfusions. In the same vein, a heart patient with no understanding of nutrition and its role in health may not "believe" that a change in diet would be helpful, and consequently would refuse this intervention. "The question can't be: Are there associations between health and belief?" says David Hufford, PhD, from Pennsylvania State Medical School. "The question is: What are they?"

In another instance, the researcher was called as the patient was about to leave the area (bed) where her six-month-old baby had died. She said, "Ndifuna ukwazi okokuba ndiyakulinkwa ilungelo lokumlanda apha phambi kokuba singcwabe." This means, "I would like to understand whether we will be given permission as a family to fetch him before burial according to tradition."

I had to explain to the patient that because the family was staying far away, the hospital could wait as other patients needed to be accommodated and arrangements could be made even when the deceased is fetched from the hospital mortuary. The patient understood the importance of taking other patients' needs into consideration without feeling that her beliefs were being undermined. In summary, all these examples reveal the influence of socio-cultural belief in healthcare. Based on the discussion, the following became clear:

Understanding how social, structural, psychological, and cultural factors affect physical health, being sensitive to these factors can make an important difference in health outcomes (Delgado et al., 2005). Beliefs affect how and from whom a person will seek care, how self-care is managed, how health choices are made, and often, how a patient respond to a specific therapy (Cooper \& Lesser, 2008; Delgado et al., 2005) [11]. 
Overall, the results confirm published studies about "Cross Cultural Medicine". In an article published in American Family Physician in December 2005, the authors stated cultural competency is an essential skill for family physicians and initial interview should elicit the patient's perception of the illness and any potential cultural conflicts between the physician and patient. This includes differing attitudes towards time and what is important in life. The previous quotes cited by the participants clearly indicate the importance of cultural sensitivity and the importance of language. Cultural understanding is imperative and the ability to speak the language is essential.

A variety of studies conducted in Burkina Faso, South Africa, Togo and Nigeria indicate blood donors harbor unfounded fears (Olaiya, Alakija, Ajala \& Olatunji, 2004) [29]. Most of them are afraid of knowing their HIV serologic status; fear being infected with diseases, and many hold the erroneous belief that donating blood may cause weight loss, high blood pressure or even death (Olaiya et al., 2004) [29].

In African countries many people are categorized in terms of an undifferentiated group, dictated by their "culture" which can be assumed primitive and superstitious compared to Western conceptualisations of health, illness, coping and stress. There is a construct that the "African mind" is an object of psychological knowledge, essentially vulnerable to social change (Lucas \& Barrett, 1995) [30]. The prioritisation of Western orientations in healthcare makes it difficult for indigenous people to access healthcare services without being stripped of their origin.

Lum (1997) [31] argues if clinical social workers are to provide patient orientated services, they must find indigenous interventions that match social and cultural values of the local people. Discrepancies between languages spoken by patients and mental health practitioners-as much as alleged lack of capacity for "insight"-African patients might be better treated via the application of psycho-pharmacological medication plus the application of more "culture" through indigenous healing practices.

In recent years, several developmental changes have come into being. These adjustments have chiefly been in the areas of education, urbanisation, economic improvement, subsequent changes in the standard of living and the adoption of Western religious practices. These changes have had enormous effect on the traditional structure of the Xhosa people especially in the practice of funeral rites. Funeral rites have become most elaborate since both traditional and modern ceremonies are performed at each funeral in the urban areas.

\section{Recommendations}

Sarangi (2001) [32] asserts communicative interaction in expert healthcare systems is an important component. The researcher attests to Sarangi's statement as this view was born out of the aforementioned quotes. Based on study findings, the following recommendations to social workers practicing in healthcare facili- 
ties are made:

Interactive relationship:

- Ask your patients questions such as "Who else is involved in your healthcare? What is your belief system? Who makes up your support system?"

- Ensure your patients understand your language.

- Provide information in simple terms.

- Record the proceedings, writing information in the patient's healthcare card

- Furthermore, healthcare facilities should establish formal guidelines available for use by all healthcare professionals, depending on the dominant sociocultural beliefs in the catchment area.

\section{Conclusions}

This study explored and described the socio-cultural beliefs influencing healthcare at a South African public hospital. The overall aim of the paper is to encourage and recommend social workers and other healthcare professionals to become more sensitive to socio-cultural issues, considering the influence may have in providing healthcare.

Even though this paper specifically deals with socio-cultural beliefs and practices, it should be kept in mind that there are patients who do not adhere to any particular cultural belief. These patients equally deserve respect and understanding. Care should be taken not to assume when a patient declares to being "non-religious", this person will have nothing to do with religious practices.

General guidelines related to socio-cultural beliefs should be considered and provided as guidelines to enable social workers and other members of the multi-professional team in a healthcare setting to optimize patient care.

\section{Limitations of the Study}

Qualitative studies have both strengths and weaknesses (De Vos et al., 2006) [32]. The current study's sample and context prohibit the possibility of generalising the findings in another setting. For instance, all interviews were conducted in one public healthcare facility. However, the richness of the data provided the researcher with much insight into the experiential world of the participants. Furthermore, some participants may have provided the researcher with socially desirable answers. The researcher addressed this problem by ensuring each participant understood there is no right and wrong answer.

\section{References}

[1] Petrus, S.T. and Bogopa, B.D. (2007) Natural and Supernatural: Intersections between the Spiritual and Natural Worlds in African Witchcraft and Healing with Reference to Southern Africa. Indo-Pacific Journal of Phenomenology, 7, 11. https://doi.org/10.1080/20797222.2007.11433943

[2] Ghiasuddin, A., Wong, J. and Siu, A. (2016) Complementary and Alternative Medicine Practices, Traditional Healing Practices, and Cultural Competency in Pediatric Oncology in Hawaii. Journal of Integrative Medicine, 14, 374-379. 
https://doi.org/10.1016/S2095-4964(16)60267-6

[3] Banks, J.A. and McGee, C.A. (1989) Multicultural Education. Allyn \& Bacon, Boston.

[4] Yen, J. and Willbraham, L. (2003) Discourse of Culture and Illness in South African Mental Healthcare and Indigenous Healing. Journal of Transcultural Psychiary, 40, 542-561. https://doi.org/10.1177/1363461503404005

[5] Armenakis, A. and Kiefer, C. (2007) Social and Cultural Factors Related to Health. Global Education Consortium, Atlanta, 1-94.

[6] Marquit, M. (2006) Faith Healing. Gale Cengage Learning, Farmington Hills.

[7] Sobiecki, J.F. (2016) South African Traditional Medicine. http://www.ethnobotany.co.za/index.php/healing/african-traditional-medicine

[8] Webster, M. (2015) A Dictionary of Concepts. www.merriam-webster.com/dictionary/belief

[9] Juckett, G. (2005) Cross-Cultural Medicine. American Family Physician, 72, $2267-$ 2274.

[10] Dorfmann, R.A., Meyer, P. and Morgan, M.L. (2012) Paradigms of Clinical Social Work: Emphasis on Diversity. Brunner-Routledge, New York.

[11] Sheafor, B.W. and Horejsi, C.R. (2010) Techniques and Guideline for Social Work Practice. 8th Edition, Pearson Education, Boston.

[12] Cooper, M.G. and Lesser, J.G. (2008) Clinical Social Work Practice. Pearson Education Publishers, Boston.

[13] Seupaul, V. and Jones, D. (2005) Global Standards for the Education and Training of the Social Work Profession. International Journal of Social Welfare, 14, 218-230. https://doi.org/10.1111/j.1468-2397.2005.00362.x

[14] Ginger, J.N. and Davidhizar, R. (1998) Transcultural Nursing: Assessment and Intervention. Journal of Urology, 73, 487-493.

[15] Kangwa, C. and Catron, R. (2011) Traditional Healing and Western Medicine: Segregation or Integration?

[16] Turner, A. (2013) South Africa's Largest Hospital: Chris Hani Baragwanath. http://www.healthcareglobal.com/hospitals/301/s-Largest-Hospital:-Chris-Hani-Bar agwanath

[17] Patel, L. (2005) Social Welfare \& Social Development in South Africa. Oxford University Press Southern Africa, Cape Town.

[18] South African Council for Social Services Professions (2012) Policy Guidelines for Course of Conduct, Code of Ethics and the Rules for Social Workers. SACSSP Publishers, Pretoria.

[19] Nasw, N.A. (2001) NASW Standards for Cultural Competence in Social Work Practice. National Association of Social Workers, Washington DC.

[20] Arrendondo, P. and Toporek, B. (2004) Multicultural Counseling Competencies: Ethical Practice. Journal of Mental Health Counseling, 26, 44-55. https://doi.org/10.17744/mehc.26.1.hw2enjqve2p2tj6q

[21] Carter, R. (1995) The Influence of Race and Racial Identity in Psychotherapy. John and Wiley Sons Publishers, New York.

[22] Horwitz, S. (2013) Baragwanath Hospital, Soweto: A History of Medical Care. Wits University Press, Johannesburg.

[23] Babbie, E.R. and Mouton, J. (2010) The Practice of Social Research. Oxford Univer- 
sity Press, Oxford.

[24] Crabtree, B.F. (1999) Doing Qualitative Research. 2nd Edition, Sage, Thousand Oaks.

[25] Creswell, J.W. (1994) Research Design: Qualitative, Quantitative and Mixed Methods Approaches. Sage, Thousand Oaks.

[26] Strydom, H. and Venter, L. (2002) Sampling and Sampling Methods. In: De Vos, A.S., Ed., Research at Grass Roots: For the Social Sciences and Human Service Profession, Van Schaik, Pretoria, 197-211.

[27] Delgado, M.J. and Rohani, M. (2005) Social Work Practice in Immigrants and Refugee Centres in the United States. Allyn \& Bacon Publishers, Boston.

[28] Olaiya, M.A. and Olantunji, R.O. (2004) Knowledge, Attitudes, Beliefs and Motivations towards Blood Donation among Blood Donors in Lagos, Nigeria. Transfusion Medicine, 14, 13-17. https://doi.org/10.1111/j.0958-7578.2004.00474.x

[29] Lucas, R.H. and Barrett, R. (1995) Interpreting Culture and Psychopathology: Primitivist Themes in Cross-Cultural Debate. Culture, Medicine and Psychiatry, 19, 287-326. https://doi.org/10.1007/BF01381915

[30] Lum, D. (1997) Should Programs and Service Delivery Systems Be Culture-Specific in Their Design? In: Deanda, D., Ed., Controvential Issues in Multiculturalism, Allyn \& Bacon Publishers, Bostom, 54-71.

[31] Sarangi, S. (2001) A Comparative Perspective on Social Theoretical Accounts of the Languageaction Interrelationship. In: Coupland, N., Sarangi, S. and Candlin, C., Eds., Sociolinguistics and Social Theory, Longman, London, 29-60.

[32] De Vos, A., Strydom, H., Fouche, C. and Delport, C. (2011) Research at Grass Roots: For Social Sciences and Human Services Professions. Van Schaik Publishers, Pretoria.

\section{Scientific Research Publishing}

Submit or recommend next manuscript to SCIRP and we will provide best service for you:

Accepting pre-submission inquiries through Email, Facebook, LinkedIn, Twitter, etc. A wide selection of journals (inclusive of 9 subjects, more than 200 journals)

Providing 24-hour high-quality service

User-friendly online submission system

Fair and swift peer-review system

Efficient typesetting and proofreading procedure

Display of the result of downloads and visits, as well as the number of cited articles

Maximum dissemination of your research work

Submit your manuscript at: http://papersubmission.scirp.org/

Or contact jss@scirp.org 